\title{
Long-wave radiation balances of grassy surface and bare soil in Wrocław
}

\author{
Krystyna Bryśs ${ }^{1, *}$, Tadeusz Bryś2 ${ }^{2}$ and Hanna Ojrzyńska ${ }^{3}$ \\ ${ }^{1}$ Wroclaw University of Environmental and Life Science, Faculty of Environmental Engineering \\ and Geodesy, pl. Grunwaldzki 24, 50-363 Wrocław, Poland \\ ${ }^{2}$ Polish Geophysical Society, Wrocław Division, pl. Grunwaldzki 24, 50-363 Wrocław, Poland \\ ${ }^{3}$ Wroclaw University, Faculty of Earth Sciences and Environmental Management, \\ pl. Uniwersytecki 1, 50-137 Wroclaw, Poland
}

\begin{abstract}
The paper goal is to show diurnal, seasonal and year to year variability of long-wave radiation balances of two contrasting types of active surfaces - grassy and bare soil in the context of bioclimatic and ecological role of plant areas in a big city. The analyses was conducted on example of Wrocław (SW Poland) and the experimental results were obtained from about twelve-year period of measurements. The average annual values of fluxes of the main components of these long-wave balances reached: $368.6 \mathrm{~W} / \mathrm{m}^{2}$ for the long-wave radiation of bare soil, $363.6 \mathrm{~W} / \mathrm{m}^{2}$ for the long-wave radiation of grassy surface and $322.9 \mathrm{~W} / \mathrm{m}^{2}$ for the downward atmospheric radiation. These differences between values of bare soil and grassy surfaces varied during the year from negative values in winter to positive values in spring and the summer. The final conclusion of the study is an important empirical argument for urban planning to extend share of plant areas in cities and urban agglomerations.
\end{abstract}

\section{Introduction}

The urban areas consist with many different surfaces with both natural and anthropogenic features. Such areal mosaic influences not only on specific features of urban landscapes but also on a comfort of the city residents life. The significant bioclimatic, recreational and ecological role in urban agglomerations pertain to green spaces, green ways, greenbelts etc., in which the different grassy terrains have a big share. The sustainable and pro-ecological development policies of urban spaces should serve a comfort, health and safety of the city inhabitants. These rules should impact both on directions of the urban planning and have strong and efficient grounds [1]. For this purpose, scientific researches on natural, environmental determinants of the functioning of different green spaces in the cities are undertaken, among which the analysis of climatic and soil factors play a major role. The most important presence of sunlight and water for the life and development of plants can be expressed in the form of radiation, heat and water balances, which are mutually related [2]. The radiation balance, which is directly related to the solar irradiance of Earth's surface, is

* corresponding author: krystyna.brys@up.wroc.pl 
of fundamental importance here, as an energy determinant of the other two balances. It consists of two main parts - short-wave and long-wave radiation balances. The term of an active surface or a soil (vegetation, water) boundary layer describes a several $\mathrm{mm}$ of thickness subsurface layer of soil, plant cover or water where the solar energy is converted into the heat [3-5]. This layer is responsible for the heat transfer between the atmosphere and the ground (vegetation cover or water area) and vice versa [1-5]. The physical features of an active surface depend on types and state of soil, vegetation or water areas and they influence on their thermal characteristic, which variability is determined by the solar irradiation balance (net radiation). This paper presents the dynamic behavior of long-wave radiation fluxes and their share in long-wave radiation balances of the two contrasting active surfaces - grassy and bare soil in the weather conditions of Wroclaw (SW Poland).

\section{Test methods for the research area}

The long-wave radiation balance $L^{*}$ of the Earth's active surfaces consists of two components - the heat radiation from these surfaces into atmosphere $(L \uparrow)$ and the return heat radiation from atmosphere (air and clouds), which is directed into these surfaces $(L \downarrow)$. The variability of values of these components is an indicator of weather and climatic dynamics, especially when is analysed in relation to the short-wave radiation balance $\left(K^{*}\right)$. The comparison of the long-wave radiation balances of two contrasting active surfaces - the grass and the field without plant cover (bare soil) is significant in this context, because the vegetation cover executes an important ecological and bioclimatic role by a moderating influence on some features of meso- and topo-climate $[2,3,4,6]$.

This field research was conducted in the Observatory of University of Environmental and Life Sciences in Wrocław. The observatory $\left(\varphi=51^{\circ} 07^{\prime} \mathrm{N}, \lambda=17^{0} 10^{\prime} \mathrm{E}\right.$, $\mathrm{h}=121 \mathrm{~m}$ a,s.1.) has a local climate and fluvial and brown soils which are representative for the Silesian Lowland. The interactions between climate and soils are similar to other lowland, postglacial areas of the central Europe [6].

The radiation fluxes were incessantly measured by two pyrranopyrgeometers CNR-1, which sensors were located $1.5 \mathrm{~m}$ over the bare soil and grassy fields [6,7]. The tests were conducted for about 12-year period, from August 2007 to March 2019. The variability of average and extreme values of the researched fluxes were determined in diurnal, seasonal and year-to-year scale for these two surface in the context of net radiation $Q^{*}$ values and their structure. The net radiation of the active surface is given by the following formula:

where:

$$
R_{n}=(K \downarrow-K \uparrow)+(L \downarrow-L \uparrow)
$$

$R_{n}-$ net radiation $\left(\mathrm{W} / \mathrm{m}^{2}\right)$

$(K \downarrow-K \uparrow)$ - shortwave radiation balance $\left(K^{*}\right)\left(\mathrm{W} / \mathrm{m}^{2}\right)$

$(L \downarrow-L \uparrow)$ - longwave radiation balance $\left(L^{*}\right)\left(\mathrm{W} / \mathrm{m}^{2}\right)$

$K \downarrow-$ flux of global solar radiation $\left(\mathrm{W} / \mathrm{m}^{2}\right)$

$K \uparrow-$ flux of reflected solar radiation $\left(\mathrm{W} / \mathrm{m}^{2}\right)$

$L \downarrow$ - flux of downward atmospheric radiation (return atmospheric radiation) (W/m²)

$L \uparrow-$ flux of thermal radiation from active surface to atmosphere $\left(\mathrm{W} / \mathrm{m}^{2}\right)$

The net radiation of the active surface is equal to heat balance of this surface:

where:

$$
R_{n}=Q^{*}=G+H+L E
$$

$Q^{*}$ - heat balance of the active surface $\left(\mathrm{W} / \mathrm{m}^{2}\right)$ 
$G$ - soil heat flux, which can be the heat flow from the soil surface into the soil $(\mathrm{G}>0)$ or vice versa $(\mathrm{G}<0)\left(\mathrm{W} / \mathrm{m}^{2}\right)$

$H$ - sensible turbulent heat flow from the soil surface to the atmosphere due to the turbulent air motion $\left(\mathrm{W} / \mathrm{m}^{2}\right)$

$L E$ - latent heat flow (evaporation latent or condensation) $\left(\mathrm{W} / \mathrm{m}^{2}\right)$

In this paper the flows $H$ and $L E$ are only shortly indicated as variability of air temperature and saturation deficit. The analysis of $G$ flows was made earlier [8]. The values of $L^{*}$ and their daily, monthly, seasonal and yearly fluxes were considered with regard to the weather changes and their macro-circulation genesis.

\section{Results and discussion}

The average annual courses of the net radiation $Q^{*}$ and its main components monthly fluxes of grassy surface $(g r)$ in the years 2008-2018 in Wrocław are shown in Fig. 1 (on the left). The appropriate courses for bare soil perform similar variability as in grassy surface, but with different values. The role of plant cover in forming the values of $Q^{*}$ and its components is indicated in Fig. 1 (on the right), where the values of differences $(b s-g r)$ between bare soil $(b s)$ and grassy surface fluxes are compared. The annual variations of the air temperature in Wrocław depend on the seasonal fluctuation of these radiation values and physical features of a mosaic of the municipal active surfaces. These same geophysical conditions (mainly climatic, edaphic and hydrological) and bio-physical features of the vegetation (e.g. albedo, transpiration) observed in a mosaic of natural and artificial plant cover in urban agglomerations influence also on soil, water and plant cover temperatures and their variability in different temporal and spatial scales. The thermal regime is different for various active surfaces and is characterized by dynamic of diurnal, seasonal and year to year temperature and heat flux changes, which are important for the right functioning of the natural and anthropogenic ecosystems $[2,3,6,7]$.
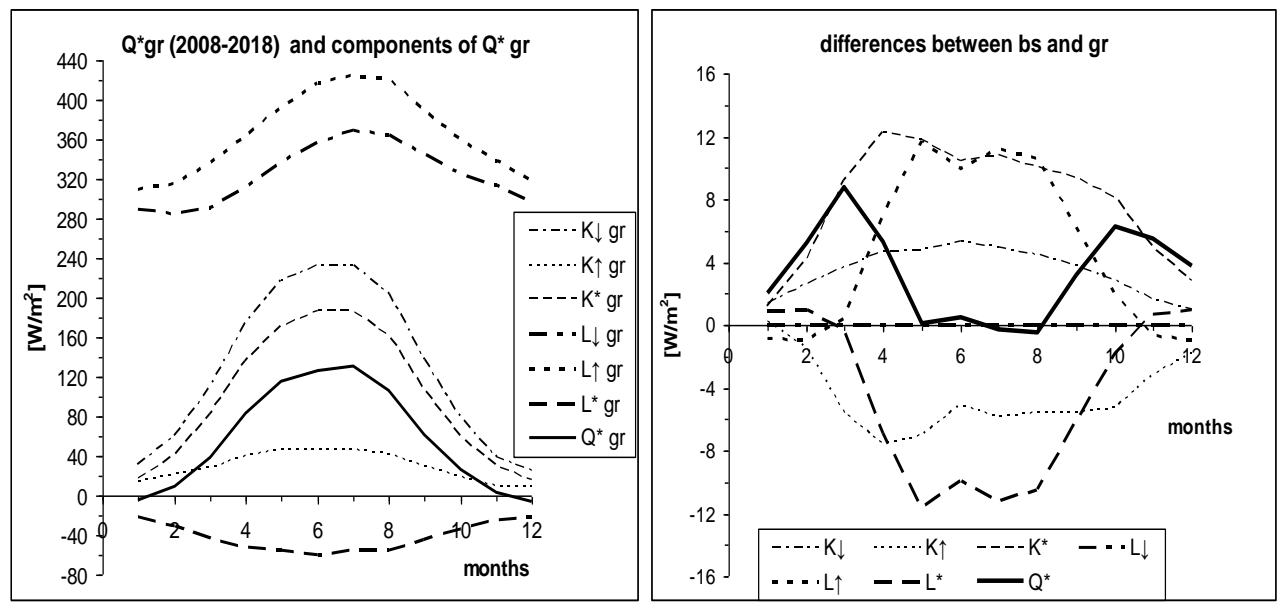

Fig. 1. The average annual courses of the net radiation $Q^{*}$ and its components (as in formula 1) monthly fluxes for grassy area $(g r)$ in the years 2008-2018 in Wrocław (on the left) and appropriate courses of the differences between values of bare soil and grassy surface ( $b s-g r)$, (on the right).

The dominance of the long-wave radiation value is clear, both for the fluxes radiated to the atmosphere from grassy surface $(L \uparrow g r)$ and bare soil $(L \uparrow b s)$ and the downward 
atmospheric radiation $(L \downarrow)$ over the short-wave solar radiation to the measured surfaces $(K \downarrow)$.

On a yearly basis, the long-wave radiation fluxes are predominant and they are approx. three times higher than the short-wave radiation $K \downarrow$ fluxes. This disproportion is related to the effective temperature of the Earth and its determinants resulting by the presence of the atmosphere and the greenhouse gases. The average annual values for the years 2008-2018 of the main components of the researched long-wave balances $\left(L^{*}\right)$ reached: $368.6 \mathrm{~W} / \mathrm{m}^{2}$ for $L \uparrow b s, 363.6 \mathrm{~W} / \mathrm{m}^{2}$ for $L \uparrow g r$. and $322.9 \mathrm{~W} / \mathrm{m}^{2}$ for $L \downarrow a t m$.

The highest average monthly short-wave solar radiation intensity $(K \downarrow)$ occurred in June and July and reached approx. $232 \mathrm{~W} / \mathrm{m}^{2}$ for grassy surface and $237 \mathrm{~W} / \mathrm{m}^{2}$ for bare soil, while for December $K \downarrow$ was about 9 times less. The highest average monthly long-wave radiation intensity from atmosphere into researched surfaces $(L \downarrow)$ occurred in July and run into approx. $370 \mathrm{~W} / \mathrm{m}^{2}$, whereas also in July the heat radiation for grassy surface $(L \uparrow g r)$ reached $424 \mathrm{~W} / \mathrm{m}^{2}$ and about $436 \mathrm{~W} / \mathrm{m}^{2}$ for bare soil $(L \uparrow b s)$.
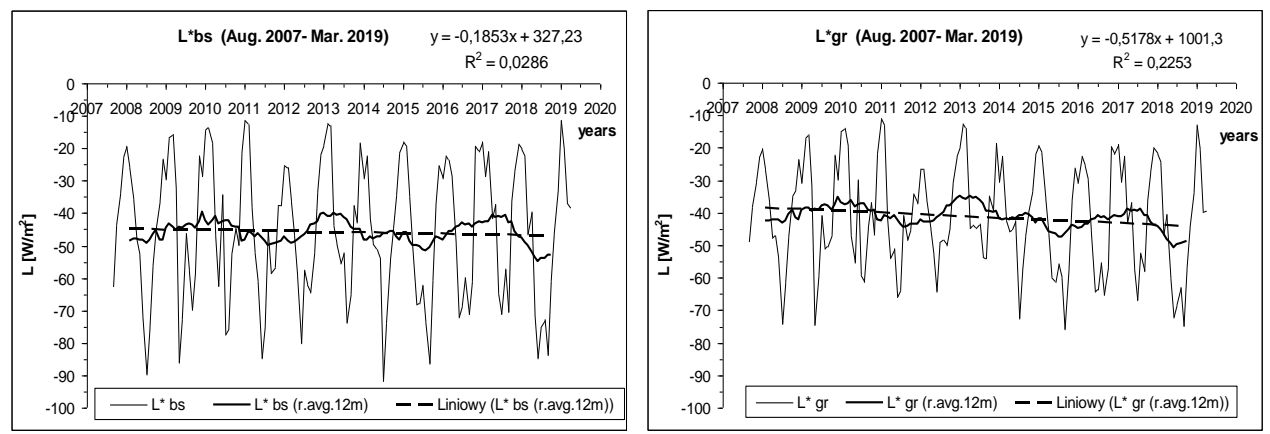

Fig. 2. The courses of monthly and twelve month running average values (r.avg.12 m) of the long-wave radiation balance for bare soil $L * b s$ (on the left) and grassy area $L * g r$ (on the right) in the period August 2007 - March 2019 in Wrocław. (Explanation: Liniowy = linear trend).

The performed in Fig. 2 courses of monthly and twelve month running average values (r.avg. $12 \mathrm{~m}$ ) of the long-wave radiation balance for bare soil $L^{*} b s$ (on the left) and grassy area $L * g r$ (on the right) in the period August 2007-March 2019 in Wrocław show not only a recurrent annual cycle of the radiation variations. These courses show also a variability from year to year in the range between winter minimum (in a sense of the modulus value) and summer maximum of $L^{*}$ both for bare soil and for grassy surface. They present also some seasonal modification (short-time oscillation) of $L^{*}$ values. The range of these annual variations is bigger for bare soil than for grassy area, because maximal (in a sense of the modulus value) average monthly values of $L^{*} b s$ are higher than for $L^{*} g r$. Such related monthly values of $L * b s$ approach $-91.7 \mathrm{~W} / \mathrm{m}^{2}$ in June 2014 and for $L^{*} g r$ only $-75.8 \mathrm{~W} / \mathrm{m}^{2}$ in August 2015 (whereas for $L * g r$ until $-86.2 \mathrm{~W} / \mathrm{m}^{2}$ ).

In the researched twelve years the statistical significant negative trend (but positive in a sense of the modulus $L^{*}$ value) occurs only in $L^{*} g r$. for its 12-month running average values $\left(r=-0.475\right.$ and $R^{2}=0.225$ for Pearson's correlation as well as $r=-0.265$ for Kendall's and $r=-0.41$ for Spearman's correlations). These all correlations are significant at the 0.01 level (2-tailed)).

To explain the genesis and basic features of long-wave radiation balances $L * b s$ and $L^{*} g r$ a detailed analysis of forming the main components of these balances in different temporal scales (from diurnal to multi-year) is necessary. The main features of seasonal and year to year variability for $L \uparrow$ and $L \downarrow$ of two researched surfaces perform Fig. 3 and Fig.4. The performed on Fig. 3 (on the right) courses of monthly and 12-month running average values of $L \downarrow \mathrm{atm}$, display seasonal variability and an inclination of the actual 12 -year 
positive trend for these running values. The statistical significant trend $\left(\mathrm{R}^{2}=0.503\right)$ of incoming long-wave radiation fluxes from the atmosphere to the researched surfaces shows the increase of the $L \downarrow$ atm values from about $320 \mathrm{~W} / \mathrm{m}^{2}$ to about $327 \mathrm{~W} / \mathrm{m}^{2}$ during the last 12 -year in Wrocław. The range of monthly $L \downarrow \mathrm{atm}$ values in these years oscillates between $257.7 \mathrm{~W} / \mathrm{m}^{2}$ in February 2018 and $374.9 \mathrm{~W} / \mathrm{m}^{2}$ in July 2014, because the lowest values of $L \downarrow$ atm perform in winter and the highest in the summer. For comparison, a weaker positive trend of $K \downarrow g r$ (Fig. 3 on the left) is connected with stronger, seasonal variations of its monthly values. because their maximum $\left(259.7 \mathrm{~W} / \mathrm{m}^{2}\right)$, which occurred in May 2018 is higher about $240 \mathrm{~W} / \mathrm{m}^{2}$ from minimum $\left(17.1 \mathrm{~W} / \mathrm{m}^{2}\right)$ in December 2018 . However, a characteristic feature of $L \downarrow \mathrm{atm}$ is a stronger year to year variability its winter minimum, which occurs between January and March and oscillates from $286.7 \mathrm{~W} / \mathrm{m}^{2}$ in March 2008 to $257.7 \mathrm{~W} / \mathrm{m}^{2}$ in February 2018 (Fig. 3 on the right). The such forming of winter $L \downarrow$ atm minimum shows its macro-circulation genesis, which probably is related to the winter index of NAO [8-10].
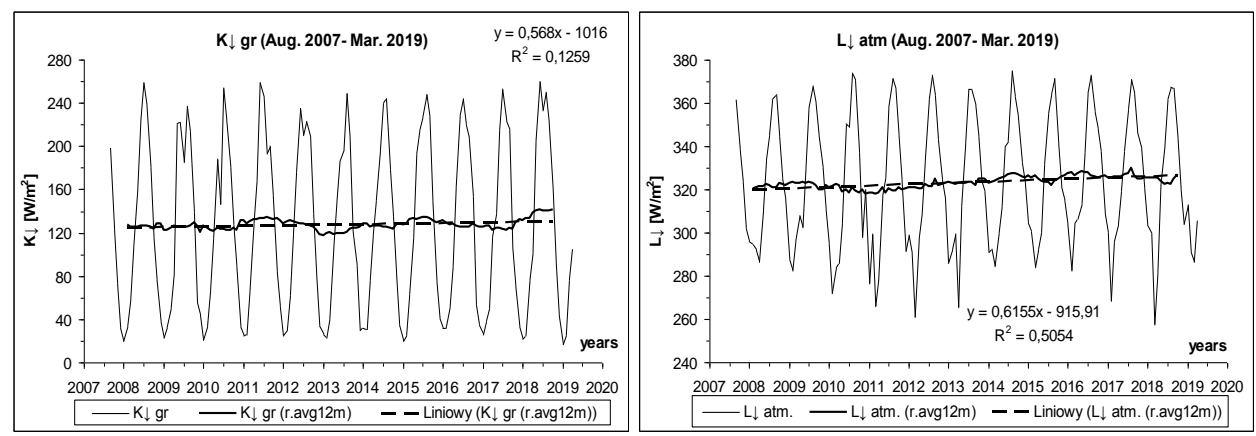

Fig. 3. The courses of monthly and twelve month running average values (r.avg.12 m) of global radiation for grassy surface $K \downarrow g r$ (on the left) and $L \downarrow$ atm. (on the right) in the period August 2007March 2019 in Wrocław (Explanation: Liniowy = linear trend).

The linear trends in Fig. 4 are positive and statistically significant, for both of $L \uparrow g r$ $\left(\mathrm{R}^{2}=0.581\right)$ and $L \uparrow b s\left(\mathrm{R}^{2}=0.373\right)$. They demonstrate that in the last twelve years a stronger increase is noted for $L \uparrow g r$ than $L \uparrow b s$, because directional coefficient of the trend's equation is bigger for the heat radiation of grassy surface $(a=1.133)$ than of bare soil $(\mathrm{a}=0.801)$. These both trends are stronger than the trend of $L \downarrow$ atm $(\mathrm{a}=0.616)$ and they influence on the course and trends of $L^{*}$ values, as is presented in Fig. 2. It is important, because a directional sign in long-wave radiation balance is positive (as a revenue in this balance) for heat radiation fluxes from atmosphere into Earth's surface and negative (as an expenditure in this balance) for the opposite fluxes $L \uparrow g r$ and $L \uparrow b s$. Therefore, a significant positive (in a sense of the modulus value) trend of $L^{*} g r$, which is shown in Fig. 2, is a result of the relatively very strong positive trend for $L \uparrow g r$. The influence of this strong trend is also visible in the context of the course of a difference $(L \uparrow b s-L \uparrow g r)$ between values of long-wave radiation for bare soil $L \uparrow b s$ and grassy area $L \uparrow g r$, for the period August 2007-March 2019 in Wrocław (Fig. 5 on the right). 

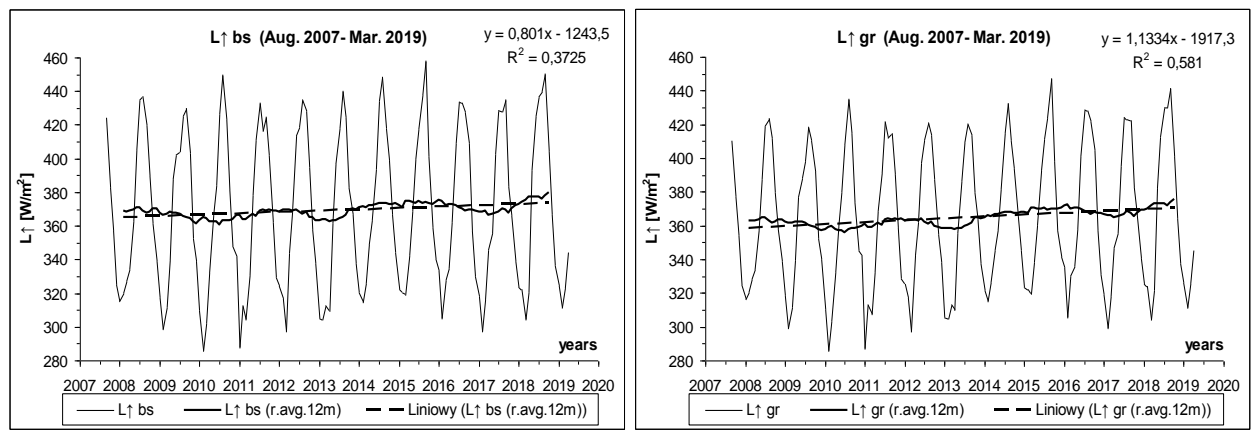

Fig. 4. The courses of monthly and twelve month running average values (r.avg. $12 \mathrm{~m}$ ) of the long-wave radiation for bare soil $L \uparrow b s$ (on the left) and grassy area $L \uparrow g r$ (on the right) in the period August 2007-March 2019 in Wrocław. (Explanation: Liniowy = linear trend).

The values of the difference $(L \uparrow b s-L \uparrow g r)$ are identical with values of the difference $\left(L^{*} b s-L^{*} g r\right.$ ) between $L^{*} b s$ and $L^{*} g r$, because these balances contain these same value of $L \downarrow$ atm The statistically significant negative trend $\left(\mathrm{R}^{2}=0.574\right)$ of this difference is characteristic only for researched 12-year period. Probably, the tendencies for a longer multi-year time can undergo changes, as it is suggested by the results of a reconstruction of this difference for Wrocław for the years 1961-2012, where the trend is positive [6]. The forming of values of the $L^{*}$ components is not only related to $K^{*} b s$ and $K^{*} g r$ and their components but also it is connected to weather conditions and short- and long-term tendencies of their variations. It is distinct visible for researched years, when the courses of $L^{*}$ and their components were compared with appropriate courses of precipitation $P$ (Fig. 5 on the left) and air temperature $T$ air (Fig. 6 on the left) and saturation deficit $d$ (Fig. 6 on the right).
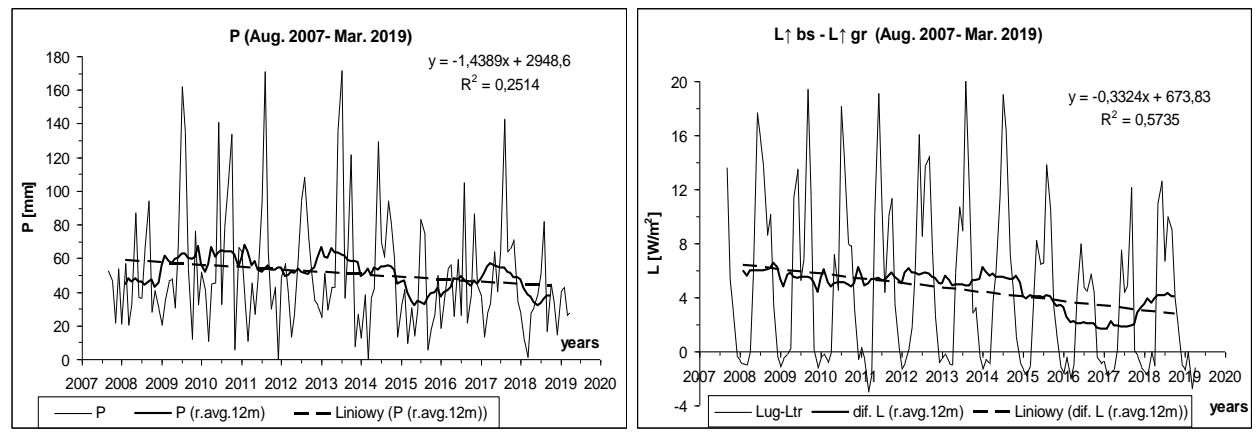

Fig. 5. The courses of monthly and twelve month running average values (r.avg.1 $2 \mathrm{~m}$ ) of the precipitation $P$ (on the left) and difference between values of long-wave radiation for bare soil $L \uparrow b s$ and grassy area $L \uparrow g r$ (on the right), as the result of a subtraction ( $L \uparrow b s-L \uparrow g r$ ), in the period August 2007-March 2019 in Wrocław. (Explanation: Liniowy = linear trend).

The negative trend of the difference $(L \uparrow b s-L \uparrow g r)$ is close related to a negative trend for precipitation $P$ and positive trends for $T$ air and saturation deficit $d$. Fig. 5 and Fig. 6 demonstrate, that in the last 12 years, occurs a natural phenomenon of relatively dry spring or summer months, which have significant influence on a right growth and life of plants. The relatively strong drought occurred in Wrocław (and also in many regions of Poland) in different years and months but in the last years their negative effects for vegetation keep up longer than in earlier years with dry periods. It was visible in the years 2015-2016, especially in August 2015 but its negative effects for life and growth of grass 
and other many-years plants occurred until to summer 2016. The effects were related, among others to adverse influence of changes of the grassy surface albedo (a relatively decrease of its values during a several months after July 2015) and a longer negative influence of the drought on buffer features of plant cover and plant roots $[2,6,7]$.
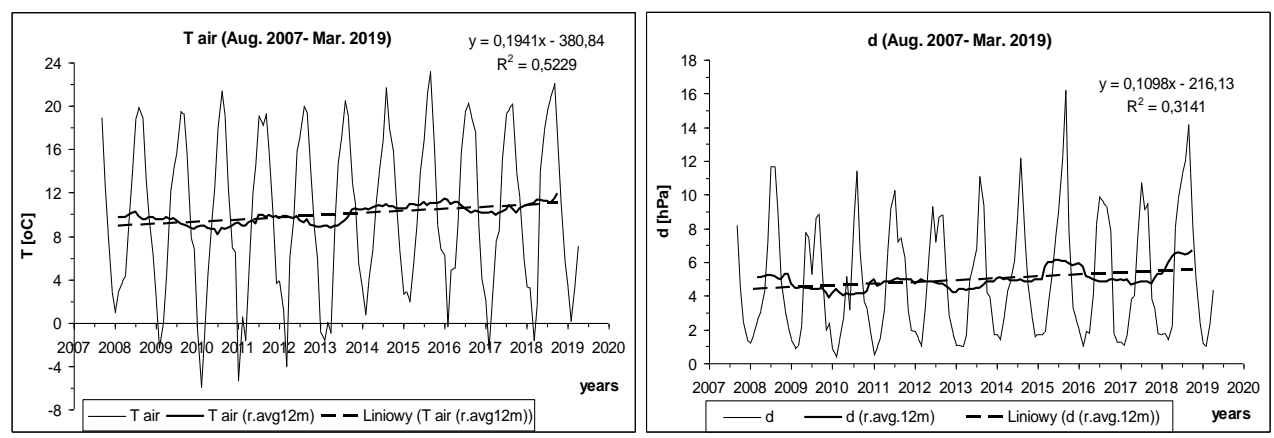

Fig. 6. The courses of monthly and twelve month running average values (r.avg.12 m) of the air temperature $T$ (on the left) and saturation deficit $d$ (on the right) in the period August 2007-March 2019 in Wrocław. (Explanation: Liniowy = linear trend).

\section{Conclusions}

The mosaic of urban surfaces in the paper was limited only to two contrasting active surfaces - without plants (bare soil) and grassy surface. Their current analysis has shown, how important is their radiation characteristics, because their dynamic temperature changes are connected with the radiation balance and its components. The comparison in this context of the long-wave radiation balances $\left(L^{*}\right)$ of these two contrasting active surfaces is significant, because the vegetation cover executes an important ecological and bioclimatic role by a moderating influence on some features of meso- and topo-climate. The experimental results obtained over a span of about twelve years (August 2007-March 2019) unbroken measurements for the environmental conditions of the central Europe, taking the edaphic features of the periphery of Wroclaw (SW Poland). The analysis, which was concentrated on diurnal, seasonal and year to year variations of the long-wave radiation balances of bare soil $(L * b s)$ and grassy surface $(L * g r)$ has exposed a large dynamic of the long-wave radiation fluxes from the researched active surfaces into the atmosphere $(L \uparrow b s$, $L \uparrow g r)$ and vice versa $(L \downarrow a t m)$. The average annual values of the fluxes of the main components of these long-wave balances reached: $368.6 \mathrm{~W} / \mathrm{m}^{2}$ for the long-wave radiation of bare soil, $363.6 \mathrm{~W} / \mathrm{m}^{2}$ for the long-wave radiation of grassy surface and $322.9 \mathrm{~W} / \mathrm{m}^{2}$ for the downward atmospheric radiation. The differences $(L \uparrow b s-L \uparrow g r)$ between values of bare soil and grassy surfaces vary during the year from negative values in winter to positive values in spring and the summer. The analysis has shown also a negative influence on radiation features of grassy surface spring and summer rain deficit, which occurred in the last several years, because this deficit aids a reduction of the difference between values of heat radiation fluxes from bare soil and grassy surface. The final conclusion of the study is an important, empirical argument for urban planning to extend share of plant areas in cities and urban agglomerations and look after their right functioning. The further analyses should be related also to heat balance, but it requires a broader and more complex research works. 


\section{References}

1. K. Fortuniak, Urban Heat Island. Energy grounds. experimental studies, numerical and statistical models (in Polish) (University of Lodz Publish, Łódź, 2003)

2. D. de Vries, Heat Transfer in Soils [in:] Heat and Mass Transfer in the Biosphere (John Willey and Sons, Washington, 1975)

3. R. Geiger, R. H. Aron, P. Todhunter, The climate near the ground ( $6^{\text {th }}$ edit., Rowman \& Littlefield Publish. Inc., Oxford, 2003)

4. T. R. Oke, Boundary layer climates (Methuen, London, 1995)

5. J. Paszyński, K. Miara, J. Skoczek, Dok. Geogr. 14 (IGiPZ PAN, Warszawa, 1999)

6. K. Bryś, Dynamics of net radiation balance of grass surface and bare soil (University of Environmental and Life Science Publish. Monographs CLXII, Wrocław, 2013)

7. K. Bryś, T. Bryś, M. A. Sayegh, H. Ojrzyńska, Energy \& Buildings, 165 (2018)

8. A. A. Marsz, A. Styszyńska, North Atlantic Oscillation and its influence on climatic and hydrological conditions of Poland (Akademia Morska, Gdynia, 2002)

9. A. A. Marsz, About oceanic conditionings of circulation and thermal nature of wintertime in Poland and the middle Europe (Akademia Morska, Gdynia, 2005)

10. K. Bryś, T. Bryś, Meteorology, Hydrology and Weather Management (2019) https://doi.org/10.26491/mhwm/103461 